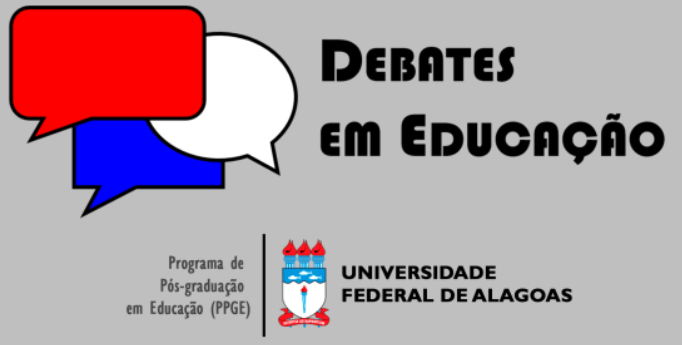

ISSN Eletrônico 2175-6600

Vol. 12 | Número Especial | 2020

Artur Gomes de Morais

9

Universidade Federal de Pernambuco (UFPE) agmorais59@gmail.com

\section{ALFABETIZAÇÃO E LETRAMENTO NA BNCC: PROBLEMAS CONCEITUAIS, LACUNAS E INADEQUAÇÕES NO QUE É PRESCRITO PARA OS DOIS ANOS INICIAIS DO ENSINO FUNDAMENTAL}

\section{RESUMO}

Através de uma análise temática de conteúdo, examinamos o que a BNCC prescreve para o ensino do sistema de escrita alfabética (SEA) e da leitura e produção de textos nos dois primeiros anos do ensino fundamental. Constatamos que a "Base" adota uma visão associacionista de aprendizagem do SEA, sugere uma progressão pouco clara do ensino das correspondências entre grafemas e fonemas e não discute as relações entre alfabetização e letramento. Além de priorizar a leitura e a produção de textos "curtos", não explicita o ensino de diferentes estratégias de compreensão leitora antes do terceiro ano do ensino fundamental. Concluímos que a BNCC deve ser substituída por um novo documento, que não induza a erros e retrocessos.

Palavras-chave: Alfabetização e letramento. Currículo. Metodologias de alfabetização. BNCC.

\section{LITERACY AT BNCC: CONCEPTUAL PROBLEMS, GAPS AND INADEQUACIES IN WHICH IS PRESCRIBED FOR THE TWO INITIAL YEARS OF ELEMENTARY SCHOOL}

\footnotetext{
ABSTRACT

Through a thematic content analysis, we examine what BNCC (Brazilian National Curricular Proposal) prescribes for teaching the alphabetic writing system (SEA) and reading and writing texts in the first two years of elementary school. We found that the BNCC adopts an associationist view of alphabetic learning from SEA, suggests an unclear progression in teaching of correspondences between grapheme-phoneme and does not discuss the relationships between alphabetic writing learning and literacy. In addition to prioritizing reading and writing of short texts, it does not make explicit the teaching of reading comprehension skills before third year of elementary school. We conclude that BNCC should be replaced by a new document, free from mistakes and without risks of setbacks.
}

Keywords: Alphabetic Learning and Literacy. Curriculum. Literacy methodologies. BNCC.

Submetido em: 06/04/2020

Aceito em: 27/06/2020

Publicado em: 10/12/2020

do http://dx.doi.org/10.28998/2175-6600.2020v I 2nEspp0 I- I6 


\section{INTRODUÇÃO}

Após a aprovação da BNCC - Base Nacional Comum Curricular por um Conselho Nacional de Educação desfigurado, em 2017, temos assistido à ação de grupos empresariais - editoras e consultorias - que, no afã de vender seus produtos e serviços, sempre repetem o discurso de que seus materiais ou cursos estão "alinhados à BNCC". Se, antes do golpe de maio de 2016, o MEC sempre afirmava que a "Base" seria um currículo a partir do qual cada município e estado teria a autonomia para criar sua própria proposta curricular, com uma margem de variação em relação ao documento nacional, hoje parece reinar um discurso de imposição única e absoluta do que está escrito "na Base". E não vemos os gestores das redes públicas reivindicarem seu direito de autoria de currículos diversificados, nem são abertos espaços para a discussão do novo currículo nacional.

Com seu propósito normativo, a BNCC prescreve um conjunto progressivo de aprendizagens, supostamente essenciais, que todos os alunos deveriam desenvolver ao longo das etapas e modalidades da Educação Básica, e que deveriam estar em conformidade com o previsto em três documentos reguladores prévios: a Constituição de 1988, a Lei de Diretrizes e Bases da Educação Nacional (LDB) de 1996 e o Plano Nacional de Educação (PNE) de 20 I4. Cabe ressaltar que, no âmbito da alfabetização, se o PNE definia que todas as crianças deveriam estar alfabetizadas até os oito anos de idade, isto é, ao final do terceiro ano do ensino fundamental, a "Base" reduziu o ciclo de alfabetização apenas aos dois primeiros anos dessa etapa e o fez sem qualquer justificativa especial ou explícita.

Este trabalho tem a intenção de analisar criticamente o que a BNCC propõe para o ensino da modalidade escrita da língua nos dois primeiros anos do ensino fundamental. Analisaremos as prescrições relativas ao ensino: i) do sistema de escrita alfabética; ii) das práticas de leitura e compreensão de textos; e iii) da produção de textos escritos.

Antes de descrever os procedimentos metodológicos e os resultados de nossas análises, faremos, inicialmente, uma explanação de como concebemos currículos e dos motivos que nos levam a defender a negociação de documentos curriculares nacionais, estaduais e municipais, enfim, de documentos que definam direitos de aprendizagem para todos os estudantes em cada etapa da educação básica. Em seguida, revisaremos alguns estudos que têm analisado a BNCC tanto em termos gerais quanto no que ela prescreve para o ensino de língua materna na educação infantil e no começo do ensino fundamental. 


\section{O QUE ENTENDEMOS POR CURRÍCULO E POR QUE SOMOS FAVORÁVEIS À NEGOCIAÇÃO DE DOCUMENTOS CURRICULARES MUNICIPAIS, ESTADUAIS E NACIONAIS.}

Se, desde as décadas finais do século $X X$, tomamos consciência de que a definição dos currículos escolares expressa, inevitavelmente, disputas políticas entre grupos sociais (APPLE, 2016) e funciona, via de regra, como instrumento de legitimação de uma seleção operada na cultura mais ampla de uma sociedade (FORQUIN, 1993), os debates subsequentes, no campo de estudos curriculares, nos levaram ao menos a dois cuidados que nos parece importante recuperar nesta breve introdução.

Por um lado, passamos a levar em conta as diferenças entre o currículo prescrito, materializado em diretrizes e documentos curriculares, e o "currículo em ação", que corresponde ao que é, de fato, realizado no quotidiano das salas de aula. Passamos a compreender que, diante das "estratégias" oficiais que visam a normatizar e padronizar o que-fazer docente, os professores usam "táticas" (CERTEAU, 1994), através das quais buscam respeitar suas crenças e saberes e assegurar o sentido de autoria de seu trabalho de ensino. Assim, expandimos nossa visão de currículo para aquilo que, no final das contas, é realizado pelos educadores e estudantes no interior das instituições escolares (e em outros espaços complementares), quando põem em prática as funções de ensinar e aprender. Leite (2013, p. 199) afirma que "[...] o currículo corresponde ao projeto global de formação escolar, entendido como plano e ação". Por outro lado, também recentemente, estudiosos do campo, como Lopes e Macedo (20 I I), têm reivindicado a polissemia do termo "currículo" e a dificuldade de defini-lo. Ante os variados sentidos que ele pode assumir, essas estudiosas ressaltam que o construto "currículo" carrega consigo a ideia de organização "[...] prévia ou não de experiências/situações de aprendizagem realizadas por docentes/redes de ensino de forma a levar a cabo um processo educativo." (LOPES; MACEDO, 20 I I, p. I9).

Assumindo, portanto, a ideia de que documentos curriculares por si sós não definem a organização das situações de ensino-aprendizagem vivenciadas em nossas escolas, mas reconhecendo que tais documentos podem influir em tal organização e em outros âmbitos, como a formação inicial e continuada de docentes, além da avaliação do desempenho escolar e as políticas de editoração de livros didáticos, no presente estudo vamos nos ater ao texto normativo denominado "Base Nacional Comum Curricular", tal como aprovado pelo Conselho Nacional de Educação (BRASIL, 20 I 8). Como vivemos num país em que diversos estudiosos do campo educacional são contrários à definição de documentos curriculares, julgamos importante explicitar por que não comungamos com esse tipo de posição.

Em diferentes textos que publicamos nos últimos anos (cf. MORAIS, 20 I 5, 20I 8; MORAIS; SILVA; NASCIMENTO, 2020), temos defendido a negociação de currículos nos quais se definam, muito claramente, os direitos de aprendizagem dos alunos a cada ano da educação básica. Diversas pesquisas 
feitas por nós e por outros estudiosos, no âmbito do ciclo de alfabetização, têm evidenciado quatro problemas decorrentes da ausência de currículos.

Em primeiro lugar, temos provas de que a ausência de documentos curriculares faz com que, no interior de uma mesma rede de ensino ou de uma mesma escola, varie, de forma aleatória, o que se ensina e se aprende num mesmo ano da educação básica. No caso da alfabetização, estudando doze turmas de crianças que estavam frequentando o segundo ano do ensino fundamental, em escolas públicas da região metropolitana de Recife - PE, Morais, Leal e Pessoa (20I3) verificaram que variavam muito as práticas de ensino de leitura e compreensão leitora, ao ponto de, em certos grupos-classe, os aprendizes nunca terem experimentado, durante todo o ano letivo, nas sessões observadas, situações de leitura silenciosa, tal como as que tinham vivenciado e voltariam a vivenciar nos dias de aplicação da Provinha Brasil, naquele ano letivo. Ressalte-se que, nas três cidades em que a pesquisa ocorreu, participaram escolas cujos desempenhos no IDEB, no ano anterior, tinham sido os mais altos (em cada município participante).

A realização daquele exame externo e de outros (como a ANA- Avaliação Nacional da Alfabetização), sem que as escolas e os docentes disponham de um currículo definidor do que se espera que seus alunos aprendam, nos parece o segundo problema e razão para defendermos que, numa república, documentos curriculares sejam negociados. Ressaltamos que, até há pouco, essa aberração que é a aplicação de avaliações em larga escala sem a definição de currículos prévios (cf. SOARES, 20l2) sempre envolveu todos os exames nacionais, da Provinha ao ENEM. E que ela promove uma outra perversão: na ausência de currículo oficial, as redes passam a treinar as crianças para acertarem os itens (habilidades) medidos pelo exame externo, tal como demonstraram as pesquisas de Miranda (20I6) e Silva (2016), ao analisarem as práticas de alfabetização em salas de aula de duas cidades do agreste pernambucano.

A terceira razão que nos faz defender a negociação de currículos decorre das evidências de que, frequentemente, não existe clara progressão do que as crianças aprendem ao longo do ciclo de alfabetização. Alguns estudos feitos em Pernambuco atestaram que não só o ensino praticado, ao final do ciclo, pode pouco diferir do que é realizado com os alunos do primeiro ano (OLIVEIRA, 20I0), como constataram que estes principiantes podem apresentar desempenho superior ao de crianças do terceiro ano - por exemplo, na produção de textos escritos (CRUZ; ALBUQUERQUE, 20I I).

Finalmente, ao lado de tudo isso, vimos, nos últimos anos, que empresários da educação começaram a vender às redes públicas os denominados "sistemas de ensino" e "apostilados", que passaram a definir, de forma padronizada, de Roraima ao Rio Grande do Sul, o que se ensina e se avalia. Ora, parece-nos evidente que a inexistência de currículos - nacionais, estaduais e municipais - só favorece essa 
entrega ao mercado do poder de definir políticas educacionais que deveriam ser democraticamente debatidas na esfera pública.

Se estivemos, nos parágrafos anteriores, usando a expressão "negociar" currículos, é porque somos radicalmente contrários à tradição autoritária de ausência de debate de tais documentos com os educadores que estão nas redes de ensino e que assumirão a organização e prática das situações de ensinoaprendizagem que tais textos deveriam, em algum grau, regulamentar. Lembremos que com a BNCC a situação não foi exatamente diferente e que a versão final, aprovada pelo CNE no final de 20।7, tinha sofrido grandes mudanças em relação à versão anterior, de maio de 2016, sem que qualquer debate público e sistemático tivesse sido realizado entre as duas ocasiões. Não nos surpreenderá, portanto, que os educadores excluídos do processo lancem mão de suas táticas (CERTEAU, 1994), para conseguirem alfabetizar com metodologias que lhes permitam se sentirem seguros e com propensão ao sucesso.

No atual caso brasileiro, grupos privados começam a vender serviços de assessoria para "ensinar", por exemplo, como se deve alfabetizar conforme a BNCC, como avaliar segundo a BNCC e outras mercadorias afins. Conhecer a fundo o que a "Base" esteve prescrevendo para o ensino de Língua, nos dois anos iniciais do ensino fundamental, parece-nos, então, obrigatório para nos posicionarmos sobre o que fazer em nossas escolas, nessa etapa da escolarização básica.

Antes, porém, revisaremos algumas pesquisas recentes sobre a BNCC, ressaltando aquelas que examinam o que a "Base" prescreve para o ensino da modalidade escrita da língua a ser praticado na educação infantil e nos dois anos iniciais do ensino fundamental.

\section{ESTUDOS RECENTES ANALISANDO O QUE A BNCC PRESCREVEU SOBRE O ENSINO DA MODALIDADE ESCRITA DA LÍNGUA NA EDUCAÇÃO INFANTIL E NA ALFABETIZAÇÃO}

Morais, Silva e Nascimento (2020) fizeram um exame minucioso do que as três versões da BNCC - divulgadas em 2015, 2016 e 2017 - propunham com respeito ao ensino da notação alfabética e da leitura e produção de textos para a etapa de educação infantil. Revisaremos aqui apenas as principais evidências por eles obtidas, quando analisaram a versão da "Base" aprovada pelo Conselho Nacional de Educação em 2017. Segundo esses autores, a BNCC, diferentemente dos documentos curriculares vigentes em países como França (FRANCE, 20I5) e Portugal (PORTUGAL, 2I6), não prescreve como tarefa da escola assegurar o direito das crianças de avançarem, até o final da educação infantil, em sua compreensão do sistema de escrita alfabética antes da entrada no ensino fundamental. Não há na "Base" qualquer objetivo explícito de promoção da consciência fonológica e tampouco se encontra a prescrição 
do ensino de letras ou sequer a exploração de palavras estáveis como os nomes próprios, uma prática já bastante consolidada nas salas de aula que atendem crianças com quatro e cinco anos.

No mesmo estudo, Morais, Silva e Nascimento (2020) evidenciaram que, no tocante às práticas de leitura de textos, a BNCC não propunha, antes do ensino fundamental, o ensino de qualquer habilidade de compreensão de leitura. Assim, o documento ignorava as evidências presentes há mais de duas décadas na literatura de que a escuta de textos lidos pelo adulto e a conversa sobre os mesmos, em sala de aula, são fontes preciosas para desenvolver a compreensão de textos escritos entre crianças da educação infantil (FONTES; CARDOSO-MARTINS, 2004).

No que concerne à produção de textos escritos, a versão aprovada da BNCC, diferentemente das anteriores, prevê um maior investimento em habilidades como expressar ideias, desejos e sentimentos por meio da linguagem escrita (escrita espontânea); recontar histórias ouvidas para registro escrito pelo professor; produzir histórias escritas (escrita espontânea) e registrar textos usando a escrita espontânea (MORAIS; SILVA; NASCIMENTO, 2020).

Jacomini, Santos e Barros (2019), ao analisarem comparativamente a proposta de alfabetização da "Base" ao que tinha sido antes proposto pelo PNE e pelo PNAIC, criticam a redução do ciclo de alfabetização a dois anos e apontam que a não priorização do letramento representaria, no texto da BNCC, um retrocesso conceitual - a redução da escrita alfabética a um código - e a desconsideração das funções sociais da leitura e da escrita. As autoras concluem que "[...] de acordo com a BNCC estar alfabetizado significa ser capaz de "codificar e decodificar" os sons da língua em material gráfico" (JACOMINI; SANTOS; BARROS, 2019, p. I I9), ressaltando o quanto esses dois últimos verbos (codificar e decodificar) assumem um sentido ambíguo no documento em foco e o descompromisso da "Base" com uma perspectiva de aprendizagem da leitura e da escrita em seus usos sociais críticos, algo tão necessário para lutarmos contra as desigualdades sociais de nosso país.

Galvão e Silva (2019), por sua vez, criticaram outros pontos no documento nacional aprovado pelo CNE em 20 17, ao examinarem o que ele prescreve para a etapa de alfabetização. Por um lado, essas pesquisadoras indicaram que a própria "visualização" das habilidades (ou objetivos) da "Base" criava problemas para a compreensão do leitor, tanto pela distribuição espacial dos mesmos, como pela falta de coerência ou critério para sua aparição em cada bloco ou coluna. No que diz respeito à "relação entre objetos de conhecimento e habilidades", as autoras observam que "as orientações sobre os objetos e habilidades descritas nos quadros, não estão colocadas de modo claro e muitas vezes, estão diluídas ao longo do texto, [...] [o que] faz com que o leitor tenha um longo trabalho para encontrá-las" (GALVÃO; SILVA, 2019, p. II). Um terceiro problema seria o "uso de expressões/conceitos empregados sem um esclarecimento ou até de forma equivocada", como é o caso da expressão "protocolo de leitura", que não é explicada no documento. Dentre suas conclusões, afırmam: 
percebemos que os quadros da BNCC preconizam um trabalho no ensino da Língua Portuguesa centrado nos aspectos linguísticos, afastando-se em muitos trechos do sentido da leitura e escrita, não fazendo uma articulação entre alfabetização e letramento. A concepção de alfabetização que encontramos na Base Nacional Comum Curricular é a concepção da língua como código. Isso representa um sério retrocesso em relação a tantos avanços nas pesquisas relacionadas à concepção de linguagem. (GALVÃO; SILVA, 2019, p. 14).

Concordando, em geral, com as análises feitas por esses autores, nosso objetivo, como já anunciado, foi analisar mais detidamente o que a "Base" prescreveu para o ensino do sistema de escrita alfabética, das práticas de leitura e compreensão de textos, assim como das práticas de escrita de textos.

\section{NOSSA METODOLOGIA}

Nossa análise documental envolveu o texto da BNCC divulgado pelo MEC em dezembro de 20 17, tal como disponibilizado no início do ano seguinte (BRASIL, 20 I 8). Para o tratamento dos dados, usamos a análise temática de conteúdo (BARDIN, 1979), na qual investigamos as seguintes categorias e subcategorias:

- ensino da escrita alfabética (promoção da consciência fonológica, estímulo à escrita espontânea, conhecimento de letras e domínio da ortografia);

- ensino de leitura (gêneros textuais sugeridos, modalidades de leitura praticadas, habilidades de compreensão leitora promovidas); e

- $\quad$ ensino de produção de textos escritos (gêneros textuais sugeridos, modalidades de escrita praticadas: tendo o adulto como escriba ou escrita espontânea de textos pela criança, habilidades de escrita de textos promovidas).

Na seção da BNCC, relativa aos anos iniciais do ensino fundamental, foram selecionados e transcritos todos os enunciados que remetiam às categorias adotadas, tendo como recorte os dois primeiros anos letivos do ensino fundamental.

\section{ANÁLISES DE RESULTADOS}

\section{I O ensino da escrita alfabética e da ortografia.}

Quando examinamos o prescrito para o ensino do sistema de escrita alfabética, vemos que, na BNCC, a própria concepção de aprendizado desse sistema revela imprecisões conceituais. Do ponto de vista terminológico, há expressões muito vagas como "construção do alfabeto", "construir o conhecimento do alfabeto", ao lado de uma terminologia associacionista veiculada por expressões como "mecânica da 
escrita/leitura", "codificar e decodificar". O emprego do termo "construção" assume uma forma bem peculiar na seguinte afırmação:

[...] alfabetizar é trabalhar com a apropriação pelo aluno da ortografia do português do Brasil escrito, compreendendo como se dá este processo (longo) de construção de um conjunto de conhecimentos sobre o funcionamento fonológico da língua pelo estudante. (BRASIL, 20 I8, p.90, grifos nossos)

Não se fala em momento algum sobre a compreensão do SEA, o que pode sugerir que a visão é realmente associacionista, pressupondo uma aprendizagem baseada na memorização e repetição das informações recebidas prontas do adulto (professora) sobre relações entre fonemas e grafemas. Como vimos nessa citação, o documento tampouco faz uma clara distinção entre "sistema de escrita alfabética" e "norma ortográfica", além de cometer outras imprecisões conceituais, tema ao qual voltaremos mais adiante.

Noutra passagem, o termo "construção" tem como complemento o conhecimento das "relações fonografêmicas":

esse processo básico (alfabetização) de construção do conhecimento das relações fonografêmicas em uma língua específica, que pode se dar em dois anos, é, no entanto, complementado por outro, bem mais longo, que podemos chamar de ortografização, que complementará o conhecimento da ortografia do português do Brasil. (BRASIL, 2018, p.91, grifos nossos).

A passagem nos suscita três observações. Em primeiro lugar, como já indicamos, apesar do uso do substantivo "construção", não há qualquer menção a um caráter evolutivo no aprendizado das relações entre grafemas e fonemas, nada que aponte para uma concepção genuinamente construtivista, de algum modo ligada a teorias que evidenciam ser esse um processo construtivo, no qual o aprendiz formula interpretações originais sobre como a escrita alfabética funciona e que não Ihe foram transmitidas no mundo escolar ou familiar (cf. FERREIRO, 1985).

Em segundo lugar, cabe ressaltar que, na passagem ora enfocada, o texto oficial afirma, sem qualquer explicação ou justificativa, que o processo de "construção" do conhecimento daquelas relações fonografêmicas poderia ocorrer em dois anos - e não em três anos, como pressupunham o PNAIC Pacto Nacional para da Alfabetização na Idade Certa (BRASIL, 20I2) e o PNE - Plano Nacional de Educação de 2014, ao qual a BNCC deveria estar alinhada.

Finalmente, nota-se, na mesma passagem, a presença do neologismo "ortografização" que, apesar de ser usado para se referir a um "processo longo", não impedirá o documento de cometer inadequações conceituais ao tratar do aprendizado da norma ortográfica. Parece-nos grave o fato de, ao referir-se às relações "fonografêmicas" de nossa língua, o texto da BNCC afirmar: "[...] Não há uma regularidade nessas relações e elas são construídas por convenção." (BRASIL, 2018, p. 9I). Por quê?

Sabemos, por um lado, que há muito mais casos regulares que irregularidades, nas relações entre letras e sons do português, sobretudo na leitura (relações grafema-fonema), como indicam Morais ( 1998) 
e Soares (2016). Por outro lado, tal como formulado na "Base", alimenta-se o clichê de que a ortografia de nossa língua seria muito irregular e se cria uma errônea oposiçãa entre "existir regularidades" e "ser definido por convenção". Como assinala Morais (2000), nas ortografias de todas as línguas, tudo é fruto de convenção, isto é, de acordo social, independentemente de existirem regras para o usuário aprender a escrever sem erros ou de ele ter que memorizar grafias que não podem ser explicadas por regras.

Ainda no âmbito do ensino da notação alfabética, o texto da BNCC possui outros problemas teóricos com implicações negativas para uma boa didatização no campo da alfabetização. Embora alguns críticos digam que a "Base" "reduz a alfabetização ao treino da consciência fonológica", na realidade o tratamento dado àquela modalidade de consciência metalinguística adotado no documento é frágil, escasso e problemático. Do ponto de vista teórico, o texto oficial trata exclusivamente de consciência de fonemas, carecendo de uma visão evolutiva, na qual a consciência do tamanho das palavras (quantidade de sílabas) e a consciência de sílabas e rimas precederia o desenvolvimento de habilidades de consciência fonêmica (cf. SOARES, 2016; MORAIS, 2019). Tampouco se discute quais habilidades metafonológicas seriam necessárias para uma criança se alfabetizar, um tema mais que urgente, ante a evidência de que métodos fônicos estão treinando diversas habilidades fonêmicas que não constituiriam requisito para um aprendiz compreender o SEA e dominar suas convenções (ARAGÃO; MORAIS, 2020).

Na realidade, as únicas passagens em que a "consciência fonológica" é mencionada, de forma diluída, na BNCC, são as seguintes:

[...] nesse processo, é preciso que os estudantes conheçam o alfabeto e a mecânica da escrita/leitura - processos que visam a que alguém (se) torne alfabetizado, ou seja, consiga "codificar e decodificar" os 90 sons da língua (fonemas) em material gráfico (grafemas ou letras), o que envolve o desenvolvimento de uma consciência fonológica (dos fonemas do português do Brasil e de sua organização em segmentos sonoros maiores como sílabas e palavras) e o conhecimento do alfabeto do português do Brasil em seus vários formatos (letras imprensa e cursiva, maiúsculas e minúsculas), além do estabelecimento de relações grafofônicas entre esses dois sistemas de materialização da língua. (BRASIL, 2018, p.89-90, grifos nossos).

Dito de outro modo, conhecer a "mecânica" ou o funcionamento da escrita alfabética para ler e escrever significa, principalmente, perceber as relações bastante complexas que se estabelecem entre os sons da fala (fonemas) e as letras da escrita (grafemas), o que envolve consciência fonológica da linguagem: perceber seus sons, como se separam e se juntam em novas palavras etc." (BRASIL, 2018, p. 90, grifos nossos).

Do ponto de vista das implicações didáticas, os trechos agora enfocados parecem sugerir que a consciência fonológica bastaria para um aprendiz "conhecer a mecânica das relações entre fonemas e grafemas", o que reforça a interpretação que fizemos, no início desta seção, de que a concepção de aprendizado da notação alfabética assumiria uma perspectiva associacionista (e não construtivista). Quando examinamos os objetivos de aprendizagem de algum modo ligados à consciência fonológica, elencados para os dois primeiros anos do ensino fundamental, encontramos apenas quatro. Curiosamente, se o primeiro que listamos abaixo parece extrapolar o conceito de consciência fonêmica, ao já cobrar a 
vinculação de letras a fonemas, os outros três se referem à consciência apenas de segmentos silábicos (e não fonêmicos):

(EF0 I LP07) Identificar fonemas e sua representação por letras. (BRASIL, 20 I8, p.97);

(EFO I LP06) Segmentar oralmente palavras em sílabas (BRASIL, 20I8, p.97);

(EFOILP09) Comparar palavras, identificando semelhanças e diferenças entre sons de sílabas iniciais;

(EFO ILPI3) Comparar palavras, identificando semelhanças e diferenças entre sons de sílabas mediais e finais (BRASIL, 20I8, p. I0I).

Com relação a esse último objetivo, cabe ressaltar que identificar sílabas mediais iguais é uma habilidade metafonológica bastante complexa e que não precisaria ser priorizada num documento como a BNCC. Por fim, ainda no que concerne ao ensino da notação alfabética, ressaltamos que a "Base" carece de uma proposta clara e exaustiva de progressão do que se deve ensinar no ciclo de alfabetização que ela reduziu a dois anos. Veja-se, por exemplo, que a aprendizagem de convenções fonema-grafema mais regulares (envolvendo o uso das letras $\mathrm{P}, \mathrm{B}, \mathrm{T}, \mathrm{D}, \mathrm{F}$ e $\mathrm{V}$ ) só é prescrita para o segundo ano do ensino fundamental, mesmo ano em que não se prescreve o domínio de algumas estruturas silábicas (como as sílabas CW e CCVC) que não aparecerão no rol de objetivos definidos para os $3^{\circ}, 4^{\circ}$ e $5^{\circ}$ anos (BRASIL, 20|8, p. $|0|)$.

No entanto, a mesma "Base" define que, já no segundo ano, as crianças deveriam:

(EF02LP08) Segmentar corretamente as palavras ao escrever frases e textos;

(EF02LP09) Usar adequamente ponto final, ponto de interrogação e ponto de exclamação (BRASIL, 2018, p.I0I).

A literatura psicolinguística tem revelado que estes aprendizados são complexos e multifacetados, exigindo mais tempo para que as crianças os consolidem. Parece-nos também preocupante que a BNCC possa contribuir para a errônea interpretação de que os sinais de pontuação tenham "empregos únicos", em lugar de poderem ser usados de forma diversificada, conforme os gêneros e os sentidos que o autor do texto intencione produzir.

\section{I.I A leitura e produção de textos escritos no começo do ensino fundamental segundo a BNCC.}

Um primeiro ponto a salientar é que, ignorando todo o debate vivido em nosso país, desde a década de 1980, a BNCC se permitiu não discutir em nenhum momento as relações entre letramento e alfabetização. Documentos produzidos previamente pelo MEC e adotados em programas de formação continuada de alfabetizadores desenvolvidos em nível nacional - como o Pró-Letramento (BRASIL, 2009) e o PNAIC (BRASIL, 20I2) - investiram bastante em justificar a opção por um ensino que assumisse a 
proposta de "alfabetizar letrando" como um meio de assegurar a nossas crianças o direito de, cedo, ampliarem sua imersão na cultura escrita.

O texto da BNCC revela baixas expectativas quanto à leitura e escrita "autônomas", isto é, realizadas pelo próprio aprendiz, sem ajuda, e prescreve, explicitamente, usar-se, nos dois primeiros anos, "gêneros simples":

os gêneros propostos para leitura/escuta e produção oral, escrita e multissemiótica, nos primeiros anos iniciais, serão mais simples, tais como listas (de chamada, de ingredientes, de compras), bilhetes, convites, fotolegenda, manchetes e lides, listas de regras da turma etc. (BRASIL, 20I8, p.93, grifos nossos).

Essa prescrição nos parece bastante grave porque não se restringe apenas à leitura e produção de textos feitas autonomamente pelo aluno. Os objetivos que remetem à leitura autônoma aparecem em número e detalhamento bem mais reduzido que aqueles que implicam ler textos "em colaboração com os colegas ou com a ajuda do professor" e se restringem a alguns gêneros ("cantigas", "letras de canção" e "textos literários") citados nas práticas de linguagem vinculadas aos campos da "vida cotidiana" e "de estudo e pesquisa" (cf. BRASIL, 20।8, p. I0I e 109).

No que diz respeito a habilidades de leitura e compreensão leitora, a BNCC não detalha ou esclarece quais seriam priorizadas nos dois primeiros anos do ensino fundamental e usa o verbo "compreender" de maneira difusa, como se pode ver na formulação dos objetivos abaixo:

(EFI2LP08) Ler e compreender, em colaboração com os colegas e com a ajuda do professor, fotolegendas em notícias, manchetes e lides em notícias, álbum de fotos digital noticioso e notícias curtas para público infantil, dentre outros gêneros do campo jornalístico, considerando a situação comunicativa e o tema/assunto do texto.

(EFI2LP09) Ler e compreender, em colaboração com os colegas e com a ajuda do professor, slogans, anúncios publicitários e textos de campanhas de conscientização destinados ao público infantil, dentre outros gêneros do campo publicitário, considerando a situação comunicativa e o tema/assunto do texto.

(EFI2LPI0) Ler e compreender, em colaboração com os colegas e com a ajuda do professor, cartazes, avisos, folhetos, regras e regulamentos que organizam a vida na comunidade escolar, dentre outros gêneros do campo da atuação cidadã, considerando a situação comunicativa e o tema/assunto do texto (BRASIL, 20 I8, p. I I3, grifos nossos).

Um exame atento do documento indica que é só a partir do $3^{\circ}$ ano que são explicitadas, na "Base", diferentes habilidades de compreensão leitora que não envolvam a mera extração de informações explicitadas na superfície dos textos:

(EF35LP03) Identificar a ideia central do texto, demonstrando compreensão global;

(EF35LP04) Inferir informaç̃̃es implíitas nos textos lidos. (EF35LP05);

(EF35LP05) Inferir o sentido de palavras ou expressões desconhecidas em textos, com base no contexto da frase ou do texto (BRASIL, 20 I8, p. I I0). 
Esse "adiamento" do ensino de habilidades de compreensão leitora parece-nos inaceitável, porque, como já dito, sabemos do efeito benéfico de ensinar habilidades de compreensão leitora mesmo para crianças que ainda só escutam textos lidos pela professora no final da educação infantil. Por outro lado, interpretamos que tal "adiamento" deve ter como contraponto uma possível priorização do domínio da "mecânica" de leitura, já que, logo no início da indicação de habilidades a serem alcançadas no primeiro e segundo anos, encontramos:

(EFI2LPOI) Ler palavras novas com precisão na decodificação, no caso de palavras de uso frequente, ler globalmente, por memorização (BRASIL, 2018, p. 97).

As análises que efetuamos indicaram, ademais, que na BNCC também não se faz, para os dois primeiros anos, uma clara diferenciação entre leitura oral e silenciosa. Esta nos parece uma lacuna importante, sobretudo quando pesquisas têm demonstrado a quase ausência de práticas de leitura silenciosa no final do segundo ano nas salas de aula de nossas crianças que estudam nas redes públicas (cf. OLIVEIRA, 20I0; MORAIS, LEAL, PESSOA, 20I3), algo que, certamente, não é vivenciado por seus pares de classe média que frequentam escolas das redes privadas de ensino.

No âmbito da produção textual, encontramos na BNCC mais referências à escrita autônoma por parte dos alunos, no segundo ano do ensino fundamental. Cabe registrar, contudo, que, nos objetivos listados, as ações de "planejar" e "produzir" gêneros escritos não aparecem necessariamente vinculadas às habilidades de "revisar" ou "produzir uma edição final", como exemplifica o objetivo abaixo:

(EF02LP I8) Planejar e produzir cartazes e folhetos para divulgar eventos da escola ou da comunidade, utilizando linguagem persuasiva e elementos textuais e visuais (tamanho da letra, leiaute, imagens) adequados ao gênero, considerando a situação comunicativa e o tema/assunto do texto (BRASIL, 2018, p. 105).

\section{A TíTULO DE CONCLUSÃO}

As análises relatadas nas seções anteriores revelam que a BNCC, imposta sem debate em 2017, no que propõe para a alfabetização e para o letramento nos dois anos iniciais do ensino fundamental é um documento com problemas conceituais, com lacunas e evidentes inadequações.

Um primeiro ponto a destacar é a visível falta de organicidade e coerência quando comparamos o que lá é prescrito para as crianças de quatro e cinco anos com a análises que apresentamos neste artigo. Reduziu-se o ciclo de alfabetização aos dois primeiros anos do ensino fundamental, sem assumir, de forma explícita, o compromisso de assegurar a todas as crianças de quatro e cinco anos o direito de avançarem na compreensão do sistema de escrita alfabética e poderem começar a aprender algumas convenções grafema-fonema e fonema-grafema. Este direito, que, como já mencionado, é assegurado nos documentos curriculares de outros países, em nada é garantido na BNCC. Isto sugere uma provável falta 
de diálogo entre as pessoas ou equipes que assumiram a tarefa de redigir cada parte da "Base", chegando a uma versão final onde este tipo de incoerência se revela.

Vimos que a BNCC é conceitualmente pobre quando se trata de conceber alfabetização e consciência fonológica e que ela comete grave erro conceitual ao referir-se à ortografia de nossa língua como "extremamente irregular". O texto oficial não assume de maneira explícita uma visão associacionista de aprendizado da escrita alfabética, embora tenda a valorizar o domínio da "mecânica" da leitura de palavras e as habilidades de "codificar" e "decodificar". Por outro lado, se permite usar de forma aligeirada expressões como "construção do alfabeto" e prescreve somente para o final do segundo ano o aprendizado das relações fonema-grafema e grafema-fonema mais simples de nossa escrita, num flagrante problema de progressão didática. Ainda quanto a esse último ponto, é também evidente a ausência de prescrição de habilidades que deem conta do domínio de todas as convenções entre grafemas e fonemas de nossa língua e do domínio das diversas estruturas silábicas que compõem as palavras do português.

Sem discutir o que é letramento e qual o papel da escola em promover práticas de leitura e escrita de textos como meio de democratizar o acesso ao mundo da escrita e a imersão no universo de práticas letradas valorizadas em nossa sociedade, a BNCC propõe um ensino extremamente pobre quando o tema é leitura e compreensão de textos escritos nos dois anos a que reduziu o ciclo de alfabetização. Antes do terceiro ano do ensino fundamental, não há nenhuma explicitação de quais estratégias de compreensão leitora, cabe à escola ensinar e o repertório de gêneros a serem lidos é reduzido a "textos curtos".

Também no que concerne à escrita de textos, vimos que há menos omissão, mas que as expectativas de que as crianças possam escrever textos autonomamente também são baixas para o ciclo de alfabetização.

Ante todas essas evidências, resta-nos registrar três comentários finais.

Em primeiro lugar, resta recordar que o texto que prescrevia os direitos de aprendizagem das crianças do PNAIC - Pacto Nacional para a Alfabetização na Idade Certa (BRASIL - MEC, 20I2) era incomparavelmente superior ao que propõe a BNCC, tanto do ponto de vista teórico-conceitual, quanto no âmbito didático. $O$ documento do PNAIC era muito mais explícito quanto às habilidades a serem ensinadas e à progressão das aprendizagens a serem alcançadas, discutindo com seriedade as relações entre alfabetização e letramento e as especificidades desses dois domínios de conhecimento.

Em segundo lugar, recomendamos a todas as redes municipais e estaduais que, ao formularem seus currículos próprios, não se deixem guiar pelos erros e baixas expectativas evidenciados na BNCC. Quando examinamos propostas municipais como a da rede pública de ensino de Lagoa-Santa-MG (LAGOA SANTA, 20 I7), vemos que se revelam muito superiores ao atual documento nacional e que seria um lamentável retrocesso terem que se "alinhar à BNCC". 
Finalmente, resta-nos conclamar todos os educadores e pesquisadores envolvidos com o ensino da modalidade escrita da língua, na educação infantil e no ensino fundamental, a apontarmos a baixa qualidade da BNCC, quando os temas são alfabetização e letramento de crianças dos quatro aos oito anos de idade. E a lutarmos por ter uma outra base nacional curricular, fruto de democrático processo de negociação e calcada no que já sabemos há décadas: é possível e necessário alfabetizar e letrar ao mesmo tempo, desde o final da educação infantil, se quisermos ter um país menos desigual.

\section{REFERÊNCIAS}

APPLE, M. W. Ideologia e Currículo. Porto Alegre: Artmed, 2016.

ARAGÃO, S. S. A.; MORAIS, A.G.M. Como crianças alfabetizadas com o método fônico resolvem tarefas que avaliam a consciência fonêmica? Educação em Revista, v. 36, 2020. Disponível em: http://www.scielo.br/scielo.php?script=sci arttext\&pid=SOI0246982020000 l 00704\&lng=en\&nrm=iso. Acesso em: 2 I jun. 2020.

BARDIN, L. Análise de Conteúdo. Lisboa: Edições 70, 1979.

BRASIL Ministério da Educação. Pró-Letramento: Programa de formação continuada de professores dos anos/séries iniciais do Ensino Fundamental: Alfabetização e linguagem. Edição revista e ampliada incluindo SAEB / Prova Brasil matriz de referência / Secretaria de Educação Básica. Brasília: Ministério da Educação, Secretaria de Educação Básica, 2007.

BRASIL. Secretaria de Educação Básica. Diretoria de Apoio a Gestão Educacional. Pacto Nacional pela Alfabetização na Idade Certa. Currículo na alfabetização: concepções e princípios. Direitos de aprendizagem no ciclo de alfabetização - Língua Portuguesa. Brasília. MEC. SEB. 2012.

BRASIL Ministério da Educação. Base Nacional Comum Curricular. Brasília, 20I 8. Disponível em: http://basenacionalcomum.mec.gov.br/wp-content/uploads/2018/02/bncc-20dez-site.pdf. Acesso em: I mar. 2018.

CERTEAU, M. A Invenção do Cotidiano - Artes de fazer. Petrópolis: Vozes, 1994.

CRUZ, M. C. S.; ALBUQUERQUE, E. B. C. Alfabetização e letramento no ${ }^{\circ}$ ciclo: o que as crianças aprendem sobre a escrita a cada ano? Revista Brasileira de Estudos Pedagógicos, Brasília, v. 92, p. $126-$ | 47, jan./abr. 201 I . Disponível em: http://rbep.inep.gov.br/ojs3/index.php/rbep/article/view/2924/2659. Acesso em: 22 mar. 2018.

FERREIRO, E. Reflexões sobre Alfabetização. São Paulo: Cortez, 1985.

FERREIRO, E.; TEBEROSKY, A. Los Sistemas de Escritura en el Desarrollo del Niño. México: Siglo XXI Eds., 1979.

FONTES, M.J.; CARDOSO-MARTINS, C. Efeitos da leitura de histórias no desenvolvimento da linguagem de crianças de nível sócio-econômico baixo. Psicologia: Reflexão e Crítica, vol. 17, p. 83-94, 2004. Disponível em: https://www.scielo.br/pdf/prc/v I7nl/22308.pdf. Acesso em: I 5 mar. 2019. 
FORQUIN, J-C. Escola e cultura: as bases sociais e epistemológica do conhecimento escolar. Trad. Guacira Lopes Louro. Porto Alegre: Artes Médicas, 1993.

FRANCE. Ministere de L'education Nationale. Programme de l'École Maternelle. 20 I5. Disponível em: http://www.education.gouv.fr/cid87300/rentree-20 I 5-le-nouveau-programme-de-l-ecole-

maternelle.html. Acesso em: 4 maio 2015.

GALVAO, E. R. S.; SILVA, L. N. Um estudo sobre a BNCC, no que tange ao processo de alfabetização, concepção, objetivos de ensino e aprendizagem. In: CONGRESSO NACIONAL EM EDUCAÇÃO E PRÁTICAS INTERDISCIPLINARES, 3., 2019, João Pessoa. Anais [...]. São Paulo: Parábola, 20 I9. v. I. p. 47-6I.

JACOMINI, M.A.; SANTOS, N.F.C.; BARROS, P.M. 2019. Alfabetização, PNE e BNCC. In CÁSSIO, F.; CATELLI J. R., R. Educação é a Base? 23 educadores discutem a BNCC. São Paulo: Ação Educativa, 2019, p. 109-122.

LAGOA SANTA. Secretaria de Educação. Projeto Alfaletrar: Metas em Progressão. Lagoa Santa: Secretaria Municipal de Educação, 2017.

LEITE, C. Currículo, didática e formação de professores: algumas ideias conclusivas. In: OLIVEIRA, M. R. N. S.; PACHECO, J. A. (Org.). Currículo, didática e formação de professores. Campinas: Papirus, 2013. p. 193-207.

LOPES, A. C.; MACEDO, E. Teorias de currículo. São Paulo: Cortez, 201 I.

MIRANDA, A. P. P. Práticas de ensino de leitura e escrita no $2^{\circ}$. e $3^{\circ}$. anos do ciclo de alfabetização. 2016. Dissertação (Mestrado em Educação Contemporânea) - Universidade Federal de Pernambuco, Caruaru, 2016.

MORAIS, A. G. Ortografia: ensinar e aprender. São Paulo: Ática, 1998.

MORAIS, A. G. Ortografia: o que temos descoberto sobre este objeto de conhecimento? o que é preciso ainda investigar? Educação em Revista, Belo Horizonte, v. I, n. 3 I , p. I 53- I69, 2000.

MORAIS, A. G. Base Nacional Comum Curricular: que direitos de aprendizagem defendemos para asa crianças na Educação infantil? Revista Brasileira de Alfabetização, Vitória, v. I, n. 2, p. |6| - 173, jul./dez. 2015.

MORAIS, A. G. A republicana proposta curricular de Língua Portuguesa que Magda Soares vem construindo com os educadores de Lagoa Santa - MG: coerência e inovação. Práxis Educativa, Ponta Grossa, v. 13, n. 3, p. 857-877, set./dez. 2018.

MORAIS, A.G. Consciência fonológica na educação infantil e no ciclo de alfabetização. Belo Horizonte: Autêntica, 2019.

MORAIS, A. G.; LEAL, T.F.; PESSOA, A.C.G.O ensino da língua portuguesa no Ciclo de Alfabetização e sua avaliação pela Provinha Brasil. In MEC-INEP. Avaliações da Educação Básica em Debate: ensino e matrizes de referências das avaliações em larga escala. Brasília: INEP, 20 I3. p. I 53-I 74. 
MORAIS, A. G. ; SILVA, A. ; NASCIMENTO, G. S. Ensino da notação alfabética e práticas de leitura e escrita na educação infantil: uma análise das três versões da Base Nacional Comum Curricular. Revista Brasileira de Educação, v. 25, p. I-25, 2020.

OLIVEIRA, S. A. Progressão das atividades de Língua Portuguesa e o tratamento dado à heterogeneidade das aprendizagens: um estudo da prática docente no contexto dos ciclos. 20 I0. Tese (Doutorado em Educação) - Universidade Federal de Pernambuco, Recife, 2010.

PORTUGAL. Ministério da Educação. Direção Geral da Educação. Orientações Curriculares para a Educação Pré-Escolar. República Portuguesa, 2016.

SILVA, A. R. L. Avaliação Nacional da Alfabetização - ANA: relações entre práticas de ensino e política de avaliação da alfabetização. 20 I6. Dissertação (Mestrado em Educação Contemporânea) - Universidade Federal de Pernambuco, Caruaru, 2016.

SOARES, M. B. Não existe um currículo no Brasil. Revista Presença Pedagógica, Belo Horizonte, v. I 8 , n. 107, p. 5-13, 2012.

SOARES, M. B. Alfabetização: a questão dos métodos. São Paulo: Contexto, 2016.

\section{COMO CITAR ESSE ARTIGO}

\section{Associação Brasileira de Normas Técnicas (ABNT)}

MORAIS, Artur Gomes de. Alfabetização e letramento na BNCC: problemas conceituais, lacunas e inadequações no que é prescrito para os dois anos iniciais do ensino fundamental. Debates em Educação, Maceió, n. 12, p. 0 I-16, set. 2020. ISSN 2175-6600. Disponível em:

https://www.seer.ufal.br/index.php/debateseducacao/article/view/9955. Acesso em: dd mmm. aaaa.

\section{American Psychological Association (APA)}

Morais, A. (2020). Alfabetização e letramento na BNCC: problemas conceituais, lacunas e inadequações no que é prescrito para os dois anos iniciais do ensino fundamental. Debates em Educação, 12(Esp), O I - 6. doi: https://doi.org/I0.28998/2 I75-6600.2020vI2nEspp0 I- I6 